\section{OXYGEN MONITORING DURING LOW FLOW} ANAESTHESIA

Oliver Sykes
From the The Anaesthetics Department, St Peter's Hospital, Guildford Road, Chertsey, Surrey KT16 0PZ, UK.

Received 6 December 2009. Accepted for publication 19 January 2010.

Address correspondence to O. Sykes, The Anaesthetics Department, St Peter's Hospital, Guildford Road, Chertsey, Surrey KT16 0PZ, UK.

E-mail: otsykes@hotmail.com
Sykes O. Oxygen monitoring during low flow anaesthesia.

J Clin Monit Comput 2010; 24:141

Dear Editor,

Re: Oxygen Monitoring during Low Flow Anaesthesia

Brody's formula for estimating oxygen consumption is rarely used in low flow anaesthesia and most anaesthetists assume that $250 \mathrm{ml} / \mathrm{min}$ is sufficient for every adult. However there is a simple method of monitoring fairly accurately the oxygen consumption in real time, using the current standard equipment and monitoring in anaesthesia.

The $\mathrm{FiO}_{2}$ and End Tidal oxygen concentrations are measured almost routinely with the modern anaesthetic machines. At sea level, these figures are almost exactly the same as percentages. Therefore, if the difference between $\mathrm{FiO}_{2}$ and $\mathrm{ETO}_{2}$ is calculated as a proportion of the minute ventilation, this gives the oxygen consumption $\left(\left(\mathrm{FiO}_{2}-\mathrm{ETO}_{2}\right) \times \mathrm{MV}\right)$. I have found that the actual amount of oxygen taken up varies considerably between patients of similar weights and at different times during anaesthesia. Sometimes up to $450 \mathrm{ml} / \mathrm{min}$. This simple calculation adds to the safety of low flow anaesthesia.

Kind regards, Dr Oliver Sykes 